seen, as compared with the dimming off of those parts of the solar atmosphere which are farther removed.

Now, can we watch this? Can we study it so that we can find out all about it? Well, not entirely. The photosphere which carries the spots to which I have referred allows us certainly to see the phenomena of the spots, but then it acts as a veil that prevents us seeing anything nearer the centre of the sun, whatever it is. It practically serves as a veil for all the underlying phenomena. Also, as I have mentioned, the outer corona is only visible for a few minutes in each generation; so that, when we attempt to watch the totality of the phenomena from the top of that magnificent radius down to that part of it which cuts the photosphere, there are difficulties of every kind supervening; we can only continuously and effectively study those regions of the atmosphere just above the photosphere, or in other words the phenomena included in the inner corona.

\section{Absorption of the Sun's Atmosphere}

But in addition to this there is something else that we can do, though this work is not so valuable, as its results are too general. We can study the general absorptive effect of the whole atmosphere above the photosphere by dealing with ordinary sunlight reflected from a cloud.

The three kinds of absorption which we recognise in spectrum analysis are these. First of all, we have a selective absorption which enables us to determine the presence of the incandescent vapour of any particular metal in the atmosphere of the sun.

Next it was pointed out in the year $1873^{1}$ that the absorption of some elementary and compound gases is limited to the most refrangible part of the spectrum when the gases are rare, and creeps gradually into the visible violet part, and finally to the red end of the spectrum as the pressure is gradually increased. It looks very much as if all the permanent gases, or all gases and vapours at a temperature below that which enables them to give out bright lines or flutings, really possess this kind of absorption, and we know that the absorption of that kind at the sun is enormous, because the blue spectrum of the electric light is very much longer-six or seven or eight times-than the spectrum of the sun, because we get an ultra-violet radiation from the electric light which has been stopped in the atmosphere of the sun. As there are permanent gases in the sun's atmosphere the same conclusion is good for it also. If this absorption both here and at the sun were taken away, it is clear that the sunlight would be much bluer than it is at present. Prof. Langley, of the United States, who seems to be unaware of the results arrived at in I873, has recently made the same announcement.

There is one other kind of absorption also. We have a general absorption-an absorption working equally upon all parts of the spectrum, which we may call general absorption in its true sense-such absorption, for instance, as we should get by mixing soot with water or smoking a glass and holding it in front of the sun-this would cause a considerable dimming of the light.

We can make this general examination of the atmosphere of the sun by simply observing the spectrum of sunlight reflected from a cloud; but it will be readily understood that, although in that case we shall be able to study the indications of selective absorption and the absorption of the blue end of the spectrum due to such gases as chlorine, and the general absorption of the spectrum due to the existence of solid particles; it will still be an inquiry which will only deal with the matter in its most general aspect, and we shall not be able to localise the exact regions in which these absorptions take place. Further we may say that the result of this study of the absorption of the solar atmosphere taken as a whole is chemical and statical merely. There is nothing dynamical about it. It tells us most important facts concerning the chemical constitution of the sun's atmosphere, taken as a whole, without localising the region in which any particular substance which we find to be absorbing is absorbing ; but it does not tell us whether this atmosphere of the sun, which roughly we may accept as about a million of miles high, is in violent movement, or whether it is at rest.

There is, then, very much more to be done before we are fully in presence of the causes of the phenomena to which I have called attention, which stare us in the face every time we look at the sun, either when it is eclipsed, or when it is not.

$$
\text { J. N. LOCKYER }
$$

(To be continued.)

\footnotetext{
${ }^{1}$ Phil. Trans., 1873, vol. clxiv. part 2, p. $49^{\mathrm{s}}$
}

\section{SCIENTIFIC SERIALS}

THE numbers of the Fournal of Botany for January and February contain no papers of very great importance. Messrs. H. and J. Groves record the addition of two new species to the British Characeæ: Chara intermedia and Nitella capitata, with figures of both. - Mr. J. G. Baker attempts to trace the relationship between the British and the Continental forms of the difficult genus Rubus. - Another addition to the British flora is recorded in Equisetum littorale, by Mr. W. H. Beeby.-Most of the other articles relate to descriptive or geographical botany.

THE most important paper in the Nuovo Giornale Botanico Italiano for January is an account by Sig. F. Morini of a new disease of cereal crops caused by the attacks of a hitherto undescribed parasitic fungus, Spharella exitialis, allied to $S$. graminicula and S. Tassiana. - Sig. Pichi investigates the nature of the reddish-brown spots on the stem of Bunias Erucago, which he finds to come under the head of glandular emergences; and Sig. Cavara describes some singular anomalies and monstrosities in the flowers of Lonicera.

\section{SOCIETIES AND ACADEMIES LONDON}

Royal Society, January I4.- "The Coefficient of Viscosity of Air." By Herbert Tomlinson, B.A. Communicated by Prof. G. G. Stokes, P. R.S.

The author employed the torsional vibrations of cylinders and spheres, suspended vertically from a horizontal cylindrical bar, and oscillating in a sufficiently unconfined space. The bar was suspended by a rather fine wire of copper or silver attached to its centre, which, after having been previously subjected to a certain preliminary treatment with a view of reducing the internal molecular friction, was set in vibration.

The coefficient of viscosity of air was obtained from observations of the diminution of the amplitude of vibration, produced by the resistance of the air to the oscillating spheres or cylinders attached to the horizontal bar, arrangements having been made so that the vibration-period of the wire should remain the same, whether the cylinders or spheres were hanging from the bar or not. In deducing the value of the coefficient of viscosity from the logarithmic decrement, the author has availed himself of the mathematical investigations of Prof. G. G. Stokes. ${ }^{1}$

Five sets of experiments were made with hollow cylinders and wooden spheres, in the construction and measurement of which considerable care was taken. When the cylinders were used arrangements were made to eliminate the effect of the friction of the air on their ends. The following are the results :-

\begin{tabular}{|c|c|c|c|c|c|c|c|c|}
\hline \multirow[b]{2}{*}{$\begin{array}{l}\text { Length } \\
\text { in centi- } \\
\text { metres }\end{array}$} & \multicolumn{7}{|c|}{ Cylinders } & \multirow[b]{2}{*}{$\begin{array}{l}\text { Coefficient of } \\
\text { viscosity of } \\
\text { the air in } \\
\text { C.G.S. units }\end{array}$} \\
\hline & & $\begin{array}{l}\text { Diameter } \\
\text { in centi- } \\
\text { metres }\end{array}$ & & $\begin{array}{l}\text { Vibration- } \\
\text { period in } \\
\text { seconds }\end{array}$ & \multicolumn{3}{|c|}{$\begin{array}{c}\text { Temperature } \\
\text { of the air in } \\
\text { degrees } \\
\text { Centigrarle }\end{array}$} & \\
\hline 60.875 & & $2 \cdot 5636$ & $\cdots$ & 6.8373 & $\ldots$ & $12{ }^{\circ} 2$ & ... & $0.0001817 \mathrm{I}$ \\
\hline 60 & $\ldots$ & 0 & ... & $7^{\circ}$ & & $14^{\circ}$ & & I 22 \\
\hline $60^{\circ}$ & ... & 2.5636 & ... & 3.0198 & $\ldots$ & I $1 \cdot 69$ & $\ldots$ & 18024 \\
\hline 53 & $\cdots$ & $2 \cdot 5636$ & $\cdots$ & 2.9994 & $\cdots$ & $10 \cdot 64$ & $\cdots$ & 0.00017845 \\
\hline & & $6 \cdot 364$ & $\ldots$ & 2.8801 & $\cdots$ & $9 \cdot 35$ & $\cdots$ & $0^{\circ} 00017820$ \\
\hline
\end{tabular}

Maxwell has proved ${ }^{2}$ that the coefficient of viscosity of air is independent of the pressure and directly proportional to the absolute temperature. We can, therefore, calculate from the above data what would be the value of the coefficient of viscosity at $0^{\circ} \mathrm{C}$. ; and when this is done, in the case of each of the five sets of experiments, we obtain the following values:-

\begin{tabular}{|c|c|c|c|c|c|c|}
\hline $\begin{array}{l}\text { Set of } \\
\text { xperiments }\end{array}$ & & & & & $\mathrm{Coe}$ & $\begin{array}{l}\text { fficient of viscosity } \\
\text { of air at } 0^{\circ} \mathrm{C} \text {. }\end{array}$ \\
\hline Ist & $\ldots$ & $\ldots$ & $\ldots$ & $\ldots$ & $\ldots$ & 0.00017404 \\
\hline 2nd & $\ldots$ & $\ldots$ & $\ldots$ & $\ldots$ & $\ldots$ & 0.00017201 \\
\hline $3 \mathrm{rd}$ & $\ldots$ & $\ldots$ & $\ldots$ & $\ldots$ & $\ldots$ & 0.00017284 \\
\hline $4^{\text {th }}$ & $\ldots$ & $\ldots$ & $\ldots$ & $\ldots$ & $\ldots$ & 0.00017359 \\
\hline $5^{\text {th }}$ & $\ldots$ & $\ldots$ & $\ldots$ & $\ldots$ & $\ldots$ & 0.00017230 \\
\hline
\end{tabular}

The mean of these numbers is 0.00017296 with a probable ${ }^{r}$ See Prof. Stokes's paper "On the Effect of the Internal Friction of Fluids on the Motion of Pendulums," Trans. Camb. Phil. Soc., vol. ix. Part II., $185^{\circ}$.

${ }_{2}$ Phil. Trans., 1865, vol. clvi. Part X. 